\title{
Endometrial Volume, and Sub-Endometrial Blood Flow Indices as Predictors of Intra-Cytoplasmic Sperm Injection Success
}

\author{
Wessam M. ABUELGHAR', Abdelatif G. ELKHOLY', Ibrahim A. ABDELAZIM1,2, Ihab SERAG', \\ Khaled I. ABDALLAH', Mohamed M. AHMED ${ }^{1}$
}

Cairo, Egypt

ABSTRACT

OBJECTIVE: This study designed to evaluate the endometrial volume, and the sub-endometrial flow indices as predictors of Intra-cytoplasmic sperm injection success.

STUDY DESIGN: Fifty infertile women included in this study, and received long pituitary downregulation protocol followed by hMG controlled hyperstimulation until $\geq 3$ ovarian follicles $18-20 \mathrm{~mm}$ in diameter detected. Ovulation triggered by hCG, followed by oocytes retrieval 34-36 hours after hCG trigger. Day 2 or 3 embryo transfers done for all studied women, followed by quantitative $\beta$-hCG 14 days after the embryo transfers, and transvaginal sonography to diagnose clinical pregnancy. Studied women evaluated by the 3D ultrasound, and 3D power Doppler angiography at the day of the embryo transfers to assess the endometrial volume, and the sub-endometrial flow indices as predictors of the Intra-cytoplasmic sperm injection success.

RESULTS: The endometrial volume, sub-endometrial vascularization index, flow index, and vascularization flow index were higher in successful Intra-cytoplasmic sperm injection compared to unsuccessful ICSI group, but the difference was not significant. The ROC analysis showed that the endometrial volume and the 3D power Doppler angiography parameters (vascularization index, flow index, and vascularization flow index indices) were not conclusive for prediction of successful clinical pregnancy after the current Intra-cytoplasmic sperm injection trials.

CONCLUSION: The endometrial volume and the 3D power Doppler angiography indices were not predictive for the clinical pregnancy after the current Intra-cytoplasmic sperm injection trials.

Keywords: Endometrial volume, Sub-endometrial blood flow, Intracytoplasmic injection

Gynecol Obstet Reprod Med 2018;24(1)27-33

\section{Introduction}

Assisted reproduction techniques (ARTs) widely used to treat fertility problems, which affect approximately $7-15 \%$ of women in their reproductive age (1).

${ }^{1}$ Department of Obstetrics and Gynecology, Ain Shams University, Cairo.

${ }^{2}$ Department of Obstetrics and Gynecology, Ahmadi Hospital, Kuwait Oil Company, Kuwait.

Address of Correspondence: Ibrahim A. Abdelazim Obstetrics and Gynecology Ain Shams

University Cairo, Egypt and Ahmadi

Kuwait Oil (KOC) Company Hospital,

Kuwait.

dr.ibrahimanwar@gmail.com

Submitted for Publication: $\quad 10.09 .2017$

Accepted for Publication: $\quad 30.11 .2017$

\begin{tabular}{|c|c|}
\hline & Access this article online \\
\hline $\begin{array}{c}\text { Quick Response Code: } \\
\text { a }\end{array}$ & $\begin{array}{c}\text { Website: www.gorm.com.tr } \\
\text { e- mail: info@gorm.com.tr }\end{array}$ \\
\cline { 2 - 2 } & DOI:10.201613/GORM.2017.742 \\
\hline
\end{tabular}

How to cite this article: Abuelghar WM. Elkkholy AG. Abdelazimi İA.Serag I. Abdallah KI. Ahmed MM. Endometrial Volume, and Sub-Endometrial Blood Flow Indices as Predictors of Intra-Cytoplasmic Sperm Injection Success. Gynecol Obstet Reprod Med 2018;24(1):27-33
In spite of several improvements in the ARTs during the last three decades $(2,3)$, the clinical pregnancy, and the livebirth rates remain approximately $30-40 \%$, and $20-30 \%$; respectively $(4,5)$.

The success of the in-vitro fertilization (IVF) and intracytoplasmic injection (ICSI) cycles depends mainly on the embryo quality, uterine receptivity, and the uterine receptivity regulated by many factors including the endometrial, and the sub-endometrial perfusion $(6,7)$.

Previous studies demonstrated a positive correlation between the endometrial characteristics, and pregnancy rate after IVF/ICSI cycles, and correlated the poor uterine receptivity to impaired endometrial, and sub-endometrial blood flow (8-10).

Merce et al. and Chien et al. suggested that the endometrial blood flow reflects properly the uterine receptivity, and the absence of color Doppler mapping at the endometrial, and sub-endometrial levels associated with significant decrease in the implantation rates (11-12).

Raine-Fenning et al. found significant changes in several ultrasonographic parameters three days before ovulation including; the vascularization index (VI), and the sub-endometrial vascularization flow index (VFI). These observations 
suggest that there is specific vascular regulation during the cycle that correlates with the endometrial development, and endometrial receptivity $(13,14)$.

Also; a study of the endometrial vascular flow showed a significant increase in the endometrial vascular flow indices on the day of hCG administration in successful ICSI cycles (11).

$L^{\prime}$ 'ed'ee et al., suggest that the use of non-invasive the 3D ultrasound power Doppler angiography (US-PDA), could provide information regarding the local angiogenic processes occurring in the endometrium, and sub-endometrium before implantation (15).

So; this prospective comparative study designed to evaluate the endometrial volume (EV), and sub-endometrial flow indices as predictors of ICSI success.

\section{Material and Method}

This prospective comparative study conducted over one year, from October 2014 to November 2015. Fifty-five (55) women undergoing ICSI included in this study after informed consent, and approval of the study by the Obstetrics, and Gynecology department, Ethical Committee.

Five (5) women excluded from this study because they did not complete the follow up (no records available), and the study started with 50 women, and final statistical analysis was done at the end of the study for 47 women ( 2 no egg retrieved, and one no fertilization happened) (Figure 1).

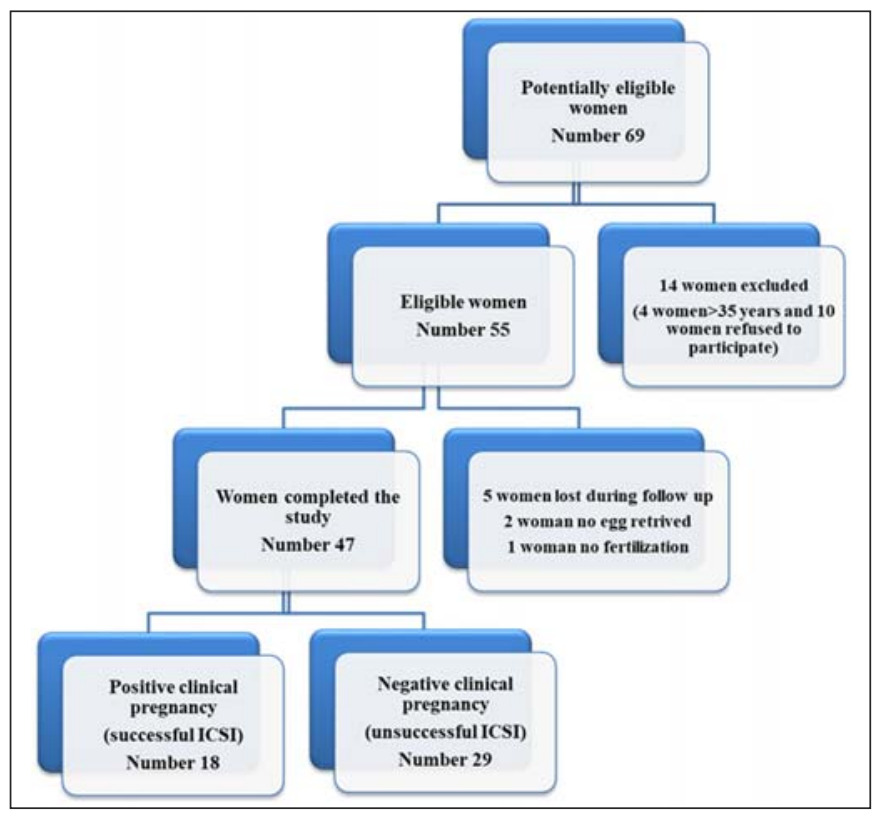

Figure 1: The study design, and the outcome of the intracytoplasmic injection (ICSI) trials

Studied women evaluated by; through history, hormonal profile (Follicle stimulating hormone (FSH), Luteinizing hormone (LH), prolactin, Thyroid stimulating hormone (TSH), Anti-Mullerian hormone (AMH), transvaginal sonography
(TVS) to detect the antral follicle count (AFC), and hysteroscopy for the uterine abnormalities.

Infertile women between 20-35 years, due to male or tubal factors, polycystic ovary syndrome, unexplained infertility with normal uterus included in this study.

Women refused to participate, $>35$ years, and women with endocrine disturbance (thyroid and/or hyperprolactinemia) excluded from this study.

Studied women received long pituitary downregulation protocol using $0.1 \mathrm{mg}$ GnRH agonist triptorelin (Decapeptyl ${ }^{\circledR}$, Ferring, Kiel, Germany) subcutaneously daily started from day 21 of the cycle, and continued until the day of hCG administration. Followed by controlled ovarian hyperstimulation $(\mathrm{COH})$ with hMG (75 IU FSH and 75 LH; Menogon ${ }^{\circledR}$, Ferring, Kiel, Germany) intramuscularly from day 2 of the cycle until $\geq$ three follicles $18-22 \mathrm{~mm}$ diameter detected during the folliculometry. When $\geq$ three follicles $18-20 \mathrm{~mm}$ in diameter detected during folliculometry, the ovulation triggered by hCG. Oocytes retrieval 34-36 hours after hCG trigger under general anesthesia, followed by day 2 or 3 embryo transfers (4-8 cell stages). Studied women received luteal phase support started at the day of embryo transfers, followed by quantitative $\beta$ hCG 14 days after the embryo transfers for diagnosis of pregnancy. Women proved to be pregnant by quantitative $\beta$-hCG, scheduled for TVS 20 days after the quantitative $\beta$-hCG for detection of gestational sac or sacs. The clinical pregnancies considered for the studied women following detection of gestational sac or sacs or histological detection of the products of conception if miscarriage occurred. Studied women evaluated by the $3 \mathrm{D}$ ultrasound for the endometrial volume, and by the 3D power Doppler angiography for detection of the sub-endometrial flow indices at the day of the embryo transfers.

Studied women classified according to the outcome of the current ICSI trial into; successful ICSI group (positive clinical pregnancy), and unsuccessful ICSI group (negative clinical pregnancy). The outcome measures the ability of the endometrial volume, and sub-endometrial flow indices to predict the success of the current ICSI trials.

The 3D power Doppler placed over the uterine longitudinal section, including the whole endometrial, and sub-endometrial areas. The following 3D power Doppler characteristics used for all studied women; normal quality of color, color gain 3.4, pulse repetition frequency of $600 \mathrm{~Hz}$, and wall motion filter of $50 \mathrm{~Hz}$. After using a scanning angle of $90^{\circ}$, the volume box was placed over the previous power Doppler image.

The time of acquisition of the volumes ranged between 15 and 20 seconds and the studied women asked to hold the breathing as much as possible to avoid the "flash type" artifacts from the respiratory or intestinal movements during the scanning time. Volumes stored and assessed subsequently in a personal computer by the same investigator. The maximum endometrial thickness obtained from the longitudinal or " $\mathrm{A}$ " 
plane defined as the greatest distance between both myo-endometrial interfaces. Through the VOCAL program, the endometrial area manually achieved from the coronal or " $\mathrm{C}$ " plane. Applying the rotational technique with $9^{\circ}$ steps, 12 endometrial "slices" obtained outlining the endometrium at the myo-endometrial junction from the fundus to the internal cervical os. The VOCAL (Virtual Organ Computer Aided Analysis) program calculates automatically the EV, and three sub-endometrial angiographic power Doppler indices; VI, flow index (FI), and VFI, which represent the number of vessels, blood flow, and endometrial perfusion; respectively $(16,17)$.

VI was measured using the ratio between the numbers of the color voxels to the number of all voxels to represent the presence of blood vessels (vascularity) in the sub-endometrium and expressed as a percentage (\%) of the endometrial volume. FI indicates the power Doppler signal intensity in the sub-endometrium, and the average intensity of the flow. VFI represent the vascularity and flow intensity (18) (Figure 2 and 3).

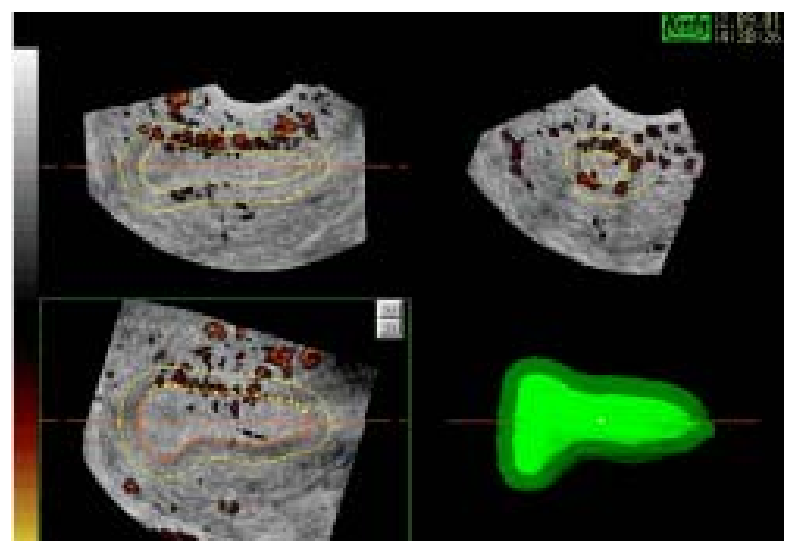

Figure 2: The $3 D$ ultrasound and 3D power Doppler angiography studies; show the identification of the myometrial-endometrial interface, and the application of $5 \mathrm{~mm}$ border around the endometrium to define the endometrial volume, and the subendometrium region for evaluation of the sub-endometrial blood flow indices.

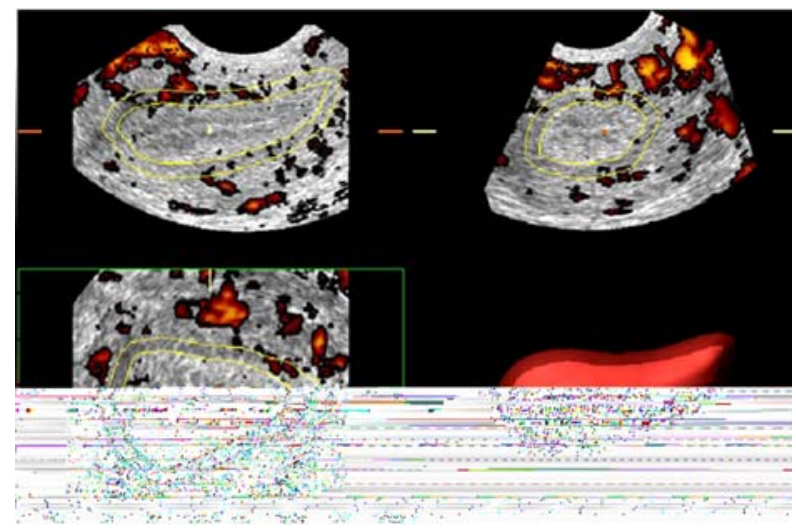

Figure 3: The $3 D$ ultrasound and 3D power Doppler angiography studies; show the identification of the myometrial-endometrial interface, and the application of $5 \mathrm{~mm}$ border around the endometrium to define the endometrial volume, and the subendometrium region for evaluation of the sub-endometrial blood flow indices.
$\mathrm{VI}=$ color voxels (total voxels - background voxels).

$\mathrm{FI}=$ weighted color voxels/color voxels.

VFI = weighted color voxels / (total voxels - background voxels).

\section{Sample size calculation}

The sample size needed to produce statistically accepted figure calculated using data from previous studies (19-22), and the Power Analysis, and Sample Size software version 08.0.9 (PASS, Kaysville, Utah), setting two-sided z-test at 0.05 type I error, and $95 \%$ confidence level. The sample size of 50 women needed to produce statistically accepted figure and would have a power of $97 \%$ to detect a difference of 0.303 between an area under the ROC curve (AUC) of 0.5 under the null hypothesis, and an AUC of 0.803 under the alternative hypothesis.

\section{Statistical methods}

The collected data statistically analyzed using the Statistical Package for Social Science (Chicago, IL, USA). Numerical variables presented as mean and standard deviation $( \pm \mathrm{SD})$, while categorical variables presented as number and percentage. Student t-test used for analysis of quantitative data. ROC (Receiver-operating characteristic) curve analysis used to evaluate the endometrial volume, and sub-endometrial flow indices as predictors of ICSI success. $P$-value $<0.05$ considered statistically significant.

\section{Results}

The mean age of the studied women was $27.9 \pm 4.2$ years, the mean BMI of the studied women was $28.3 \pm 5.3 \mathrm{~kg} / \mathrm{m}^{2}$, and the mean duration of the infertility was $4.9 \pm 3.1$ years. The ICSI trials were indicated in $76 \%(38 / 50)$ of the studied women because of primary infertility, and in 24\% (12/50) of the studied women because of secondary infertility. $24 \%$ $(12 / 50)$ of the studied women had previous ICSI trials, while, $38(76 \%)$ of the studied women had no prior ICSI trials.

The etiologies of infertility among the study population were; male factor in $58 \%(29 / 50)$, unexplained infertility in $16 \%(8 / 50)$, combined male, and female factors in $12 \%(6 / 50)$, tubal factors in $10 \%(5 / 50)$, uterine factor in $2 \%(1 / 50)$, and anovulation in $2 \%(1 / 50)$.

The outcome of the current ICSI trials was successful in $36 \%(18 / 50)$ of the studied women $(16.7 \%(3 / 18)$ twin pregnancies) and unsuccessful in $64 \%(32 / 50)$ of the studied women. The outcome of the current ICSI trials regarding; the egg retrieved, the number, and quality of the embryos transferred, and the day of the embryos transfer listed in table 1.

The studied women classified according to the outcome of the current ICSI trials into; successful ICSI group (positive clinical pregnancy), and unsuccessful ICSI group (negative clinical pregnancy). There was no significant difference between the two studied groups regarding; the age, the BMI, the 
duration, and type of infertility, and the outcome of the current ICSI trials. Also; there was no significant difference between the two studied group regarding; the number, the quality, the day of the embryo transfer, and the outcome of the current ICSI trials.

The EV, VI, FI, and VFI were higher in successful ICSI compared to unsuccessful ICSI group, but the difference was not significant (Table 2).

The ROC analysis showed; that the EV and the 3D power Doppler angiography parameters (VI, FI, and VFI indices) were not conclusive for prediction of successful clinical pregnancy after the current ICSI trials (No cutoff points with good diagnostic characteristics could be obtained) (Figure 4).

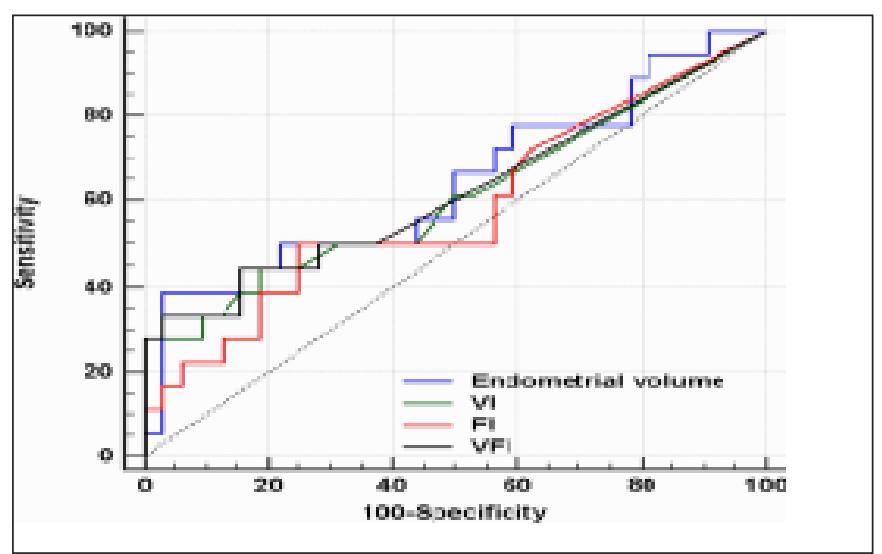

Figure 4: The ROC curves analysis for the endometrial volume, and the 3D power Doppler angiography indices (VI, FI, VFI) as predictors for the clinical pregnancy, and successful ICSI trial.

Table 1: Outcome of the current intra-cytoplasmic sperm injection trial in the studied women

\begin{tabular}{|c|c|}
\hline Variables & $\begin{array}{l}\text { Studied women } \\
\text { Number }=50\end{array}$ \\
\hline $\begin{array}{l}\text { Outcome of the current ICSI trial (number and \%) } \\
\text { Successful } \\
\text { Unsuccessful }\end{array}$ & $\begin{array}{l}18 / 50(36 \%) \\
32 / 50(64 \%)\end{array}$ \\
\hline $\begin{array}{l}\text { Egg Retrieval (number and \%) } \\
\text { No egg retrieved } \\
\text { No fertilization } \\
\text { Embryo production }\end{array}$ & $\begin{array}{l}2 / 50(4 \%) \\
1 / 50(2 \%) \\
47 / 50(94 \%)\end{array}$ \\
\hline $\begin{array}{l}\text { Number of transferred embryos (number and \%) } \\
\text { One } \\
\text { Two }\end{array}$ & $\begin{array}{l}9 / 47(19.1 \%) \\
38 / 47(80.9 \%)\end{array}$ \\
\hline $\begin{array}{l}\text { Quality of the embryos transferred (number and \%) } \\
\text { Grade A } \\
\text { Grade B } \\
\text { Grade C }\end{array}$ & $\begin{array}{l}36 / 47(76.6 \%) \\
9 / 47(19.1 \%) \\
2 / 47(4.3 \%)\end{array}$ \\
\hline $\begin{array}{l}\text { Day of the embryo transfer (number and \%) } \\
\text { Day } 2 \text { embryo transfer } \\
\text { Day } 3 \text { embryo transfer }\end{array}$ & $\begin{array}{l}8 / 47(17.02 \%) \\
39 / 47(82.98 \%)\end{array}$ \\
\hline $\begin{array}{l}\text { Number of sacs in pregnant women (number and \%) } \\
\text { One intrauterine sac } \\
\text { Two intrauterine sacs }\end{array}$ & $\begin{array}{l}15 / 18(83.3 \%) \\
3 / 18(16.7 \%)\end{array}$ \\
\hline
\end{tabular}

Data presented as number and \% (percentage). Grade A: the embryo has an optimal cell number (4 in day 2 and 8 in day 3), the cells are equal in size and there is minimal or no fragmentation. Grade B: the embryos with equal sized cells and $>15 \%$ fragmentation. Grade C: the embryos with unequal cells and $>50 \%$ fragmentation. ICSI: Intra-cytoplasmic sperm injection

Table 2: Three-dimensional ultrasound and the power doppler angiography indices in the two studied groups

\begin{tabular}{llll}
\hline Variable & $\begin{array}{l}\text { Unsuccessful ICSI } \\
\text { (Negative clinical pregnancy) } \\
\text { number }=32\end{array}$ & $\begin{array}{l}\text { Successful ICSI } \\
\text { (Positive clinical pregnancy) } \\
\text { number = 18) }\end{array}$ & $\begin{array}{l}p \text { value } \\
95 \% \text { Confidence Interval }\end{array}$ \\
\hline Endometrial volume $(\mathrm{mL})$ & $7.7 \pm 6.9$ & $12.1 \pm 11.0$ & $0.9^{*}$ \\
Vascularization index & $0.12 \pm 0.23$ & $1.49 \pm 4.44$ & $-4.4,1.2)$ \\
Flow index & $11.6 \pm 14.1$ & $19.1 \pm 21.8$ & $(-3.4,-1.4,0.7)$ \\
Vascularization flow index & $0.5 \pm 0.9$ & $1.1 \pm 4.1$ & $0.9^{*}$ \\
& & & $(-18.7,7.5,3.7)$ \\
\end{tabular}




\section{Discussion}

Implantation is a dynamic process, involving embryo apposition, and attachment to the maternal endometrium followed by invasion into the endometrial stroma (23).

Low implantation rates in-spite of transfer of "good quality" embryos should be expected if the embryos transferred in a poorly developed endometrium (23).

Implantation occurs during the period of maximal uterine receptivity, which commences 7 days after ovulation (Day 20 of an ideal and regular 28-day cycle), and lasts no more than two days (24).

Fifty (50) women undergoing ICSI included in this study to evaluate the endometrial volume, and sub-endometrial flow indices as predictors of ICSI success. Studied women were assessed using the 3D ultrasound for detection of the endometrial volume, and the 3D power Doppler angiography indices before the embryo transfers.

Although Kupesic et al., found that the pregnancy and the implantation rates were significantly lower in patients with endometrial volume $<2 \mathrm{~mL}$, and no pregnancy achieved in patients with endometrial volume $<1 \mathrm{~mL}$ or $>8 \mathrm{~mL}$ (25). The EV in this study done before embryo transfers was higher in successful ICSI compared to unsuccessful ICSI group (without any significant difference), and the ROC curve analysis showed that the endometrial volume was not predictive for the success of the ICSI trials.

Alcázar et al. reported that the endometrial volume was ineffective for predicting pregnancy in IVF program in the majority of the published studies (26). In addition; Yaman et al. found no difference in the endometrial volume between conception, and non-conception cycles on the day of hCG (27), and J"arvel" a et al. found no difference in the endometrial volume between conception cycles, and non-conception cycles, 36 hours after oocytes retrieval (19).

Schild et al. found that the endometrial volume failed to predict the outcome of the IVF cycles (20), and Yaman et al., concluded that the endometrial volume did not differ significantly in women that became pregnant from those who did not (27).

Raine-Fenning et al. found that the endometrial, and the sub-endometrial blood flows increased during the proliferative phase, reaching the maximum peak three days before ovulation and decreased again five days' post-ovulation (28).

Raine-Fenning et al. in another study concluded that the endometrial, and the sub-endometrial blood flows reduced in women with unexplained infertility irrespective the serum levels of estrogen and/or progesterone, and endometrial morphology (28).

Although, the examination of the sub-endometrial blood flow on the 1st day of the ovarian stimulation by Schild et al. documented that the VI, FI, and VFI were lower in conception cycles, Wu et al., found that the sub-endometrial VFI $>0.24$, had $83.3 \%$ sensitivity, $88.9 \%$ specificity, $93.8 \%$ positive predictive value, and $72.7 \%$ negative predictive value for prediction of successful IVF cycles $(20,21)$.

In that study VI, FI, and VFI measurements were performed before embryo transfers and found to be higher in successful ICSI compared to unsuccessful ICSI group (without any significant difference). The ROC curve analysis showed that the VI, FI, and VFI were not predictive for the success of ICSI trials.

Jarvela et al., found no difference in the endometrial/subendometrial VI, FI, and VFI, 36 hours after oocyte retrieval between conception, and non-conception cycles (19), and $\mathrm{Ng}$ et al., found no differences in the sub-endometrial VI, FI, and VFI on day of oocyte retrieval between conception, and nonconception cycles (7).

Dorn et al. found no difference in the sub-endometrial VI, FI, and VFI on the day of oocyte retrieval between pregnant, and non-pregnant women (22).

Because, the method to predict the endometrial receptivity not yet established, the 3D ultrasound parameters of the endometrium, and the sub-endometrial blood flow indices suggested as predictors of IVF success $(26,28)$.

Although; the majority of investigators assessed the subendometrial vascularization as predictors of IVF/ICSI success (7). Merce et al., decided to calculate and investigate the endometrial 3D power Doppler indices because the endometrium is the actual place of implantation (11).

In addition; it is not possible to determine the sub-endometrial vascularity accurately, in different women undergoing ICSI trials with different endometrial thickness (from 1 to $10 \mathrm{~mm})(7,9,21)$.

Merce et al., found that the endometrial vascular flow indices (VI, FI, and VFI) were significantly high on the day of $\mathrm{hCG}$ in the pregnant compared to the non-pregnant group, and concluded that the endometrial blood flow reflects the uterine receptivity accurately (11).

Although, previous studies suggested that the EV and the sub-endometrial 3D power Doppler indices were promising, non-invasive tools for prediction of the endometrial receptivity, and IVF success. This study concluded that the EV and the sub-endometrial 3D power Doppler flow indices were not predictive for the ICSI success. The endometrial 3D power Doppler flow indices may be more reliable for detection of the IVF/ICSI success because the endometrium is the actual place of implantation, and it is not possible to detect the sub-endometrial vascularity accurately, in different women undergoing ICSI trials with different endometrial thickness. 
Women refused to participate in this study was the only limitation faced during conduction of this study. Further, comparative studies comparing the endometrial 3D power Doppler angiography indices between conception, and non-conception cycles needed, because the endometrium, and not the sub-endometrial region is the actual place of implantation.

: Conflict of interest: None

\section{References}

1. Louis JF, Thoma ME, Sorensen DN, McLain AC, King RB, Sundaram R, et al. The prevalence of couple infertility in the United States from a male perspective: evidence from a nationally-representative sample. Andrology 2013;1:741-748.

2. Phillips JA, MartinsWP, Nastri CO, Raine-Fenning NJ. Difficult embryo transfers or blood on catheter and assisted reproductive outcomes: a systematic review and meta-analysis. Eur J Obstet Gynecol Reprod Biol 2013; $168(2): 121-8$

3. Martins, WP, Vieira CVR, Teixeira DM, Barbosa MAP, Dassunção LA and Nastri CO. Ultrasound for monitoring controlled ovarian stimulation: a systematic review and meta-analysis of randomized controlled trials. Ultrasound Obstet Gynecol 2014;43:25-33.

4. Gunby J, Bissonnette F, Librach C, Cowan L; IVF Directors Group of the Canadian Fertility and Andrology Society. Assisted reproductive technologies (ART) in Canada: 2007 results from the Canadian ART Register. Fertil Steril 2011; 95(2):542-7.e1-10.

5. Sunkara SK, Rittenberg V, Raine-Fenning N, Bhattacharya S, Zamora J, Coomarasamy A. Association between the number of eggs and live birth in IVF treatment: an analysis of 400135 treatment cycles. Hum Reprod 2011;26(7):1768-74.

6. Barker MA, Boehnlein LM, Kovacs P, Lindheim SR. Follicular and luteal phase endometrial thickness and echogenic pattern and pregnancy outcome in oocyte donation cycles. J Assist Reprod Genet 2009;26(5):243-249.

7. Ng EH, Chan CC, Tang OS, Yeung WS, Ho PC. The role of endometrial and sub-endometrial blood flows measured by three-dimensional power Doppler ultrasound in the prediction of pregnancy during IVF treatment. Hum Reprod 2006;21(1):164-70.

8. Al-Ghamdi A, Coskun S, Al-Hassan S, AL-Rejjal R, Awartani K. The correlation between endometrial thickness and outcome of in vitro fertilization and embryo transfer (IVF-ET) outcome. Reprod Biol Endocrinol 2008;6:37. doi:10.1186/1477-7827-6-37.

9. Ho M, Huang LC, Chang YY, Chen HY, Chang WC, Yang $\mathrm{TC}$, et al. Electroacupuncture reduces uterine artery blood flow impedance in infertile women. Taiwan J Obstet Gynecol 2009;48(2):148-51.

10. Takasaki A, Tamura H, Miwa I, Taketani T, Shimamura K,
Sugino N. Endometrial growth and uterine blood flow: a pilot study for improving endometrial thickness in the patients with a thin endometrium. Fertil Steril 2010;93 (6):1851-8.

11. Merce LT, Barco MJ, Bau S, Troyano J. Are endometrial parameters by three-dimensional ultrasound and power Doppler angiography related to in vitro fertilization/embryo transfer outcome? Fertil Steril 2008; 89(1):111-7.

12. Chien LW, Lee WS, Au HK, Tzeng CR. Assessment of changes in utero-ovarian arterial impedance during the peri-implantation period by Doppler sonography in women undergoing assisted reproduction. Ultrasound Obstetrics Gynecology 2004;23(5):496-500.

13. Raine-Fenning NJ, Campbell BK, Clewes JS, Kendall NR, Johnson IR. Quantifying the changes in endometrial vascularity throughout the normal menstrual cycle with threedimensional power Doppler angiography. Hum Reprod 2004;19(2):330-8.

14. Raine-Fenning NJ, Campbell BK, Kendall NR, Clewes JS, Johnson IR. Endometrial and subendometrial perfusion are impaired in women with unexplained subfertility. Hum Reprod 2004;19(11):2605-14.

15. L'ed'ee N, Chaouat G, Serazin V, Lombroso R, Dubanchet S, Oger P, et al. Endometrial vascularity by three-dimensional power Doppler ultrasound and cytokines: a complementary approach to assess uterine receptivity. J Reprod Immunol 2008;77(1):57-62.

16. Farrell T, Leslie JR, Chien PF, Agustsson P. The reliability and validity of three dimensional ultrasound volumetric measurements using an in vitro balloon and in vivo uterine model. BJOG 2001;108(6):573-82.

17. Raine-Fenning NJ, Campbell BK, Clewes JS, Kendall NR, Johnson IR. The reliability of virtual organ computeraided analysis (VOCAL) for the semiquantification of ovarian, endometrial and subendometrial perfusion. Ultrasound Obstet Gynecol 2003;22:633-639

18. Pairleitner H, Steiner H, Hasenoehrl G, Staudach A. Three dimensional power Doppler sonography: imaging and quantifying blood flow and vascularization. Ultrasound Obstet Gynecol 1999;14(2):139-143.

19. J“arvel“a IY, Mason HD, Sladkevicius P, Kelly S, Ojha K, Campbell S, et al. Characterization of normal and polycystic ovaries using three-dimensional power Doppler ultrasonography. J Assist Reprod Genet 2002;19(12):582590.

20. Schild RL, Holthanus S, Alquen JD. et al. Quantitative assessment of subendometrial blood flow by three-dimensional-ultrasound is an important predictive factor of implantation in an in-vitro fertilization programme. Hum. Reprod 2000;15:89-94.

21. Wu HM, Chiang CH, Huang HY, Chao AS, Wang HS, Soong YK. Detection of the sub-endometrial vascularization flow index by three-dimensional ultrasound may be useful for predicting the pregnancy rate for patients un- 
dergoing in vitro fertilization- embryo transfer. Fertil Steril 2003;79:507-511.

22. Dorn C, Reinsberg J, Willeke C, Wendt A, Van Der Ven H, Schild RL.Three-dimensional power Doppler ultrasound of the subendometrial blood flow under the administration of a contrast agent (Levovist). Arch Gynecol Obstet 2004;270:94-98.

23. Achache $\mathrm{H}$ and Revel A. Endometrial receptivity markers, the journey to successful embryo implantation. Hum Reprod Update 2006;12(6):731-46.

24. Cavagna M, Mantese JC. Biomarkers of endometrial receptivity-a review. Placenta 2003;24 Supp B:S39-47.

25. Kupesic S, Bekavac I, Bjelos D and Kurjak A. Assessment of endometrial receptivity by transvaginal color Doppler and three-dimensional power Doppler ultrasonography in patients undergoing in vitro fertilization procedures. J Ultrasound Med 2001;20(2):125-34.

26. Alcázar JL, Mercé LT, Manero MG, Bau S, López-García G. Endometrial volume and vascularity measurements by transvaginal 3-dimensional ultrasonography and power Doppler angiography in stimulated and tumoral endometria: an interobserver reproducibility study. J Ultrasound Med 2005;24(8):1091-8.

27. Yaman C1, Jesacher K, Pölz W. Accuracy of three-dimensional transvaginal ultrasound in uterus volume measurements; comparison with two-dimensional ultrasound. Ultrasound Med Biol 2003;29(12):1681-4.

28. Raine-Fenning NJ, Campbell BK, Clewes JS, Kendall NR, Johnson IR. Defining endometrial growth during the menstrual cycle with three-dimensional ultrasound. BJOG 2004;111(9):944-9. 